\title{
Exogenous endophthalmitis caused by Enterococcus casseliflavus: A case report and discussion regarding treatment of intraocular infection with vancomycin-resistant enterococci
}

\author{
Byron $M$ Berenger $M D^{1,2}$, Shobhana Kulkarni $M D^{3,4}$, Brad J Hinz $M D^{5}$, Sarah E Forgie $M D^{1,6}$
}

BM Berenger, S Kulkarni, BJ Hinz, SE Forgie. Exogenous endophthalmitis caused by Enterococcus casseliflavus: A case report and discussion regarding treatment of intraocular infection with vancomycin-resistant enterococci. Can J Infect Dis Med Microbiol 2015;26(6):330-332.

BACKGROUND: Endophthalmitis caused by enterococci is rare, and cases involving vancomycin-resistant enterococci are even more so. Due to the poor bioavailability of many antibiotics in the vitreous chamber, special considerations are required when choosing antibiotics to treat these infections. The authors report the first case of exogenous endophthalmitis caused by Enterococcus casseliflavus via the unique mechanism of high-velocity water stream trauma from a toy water gun.

A previously healthy four-year old boy presented with endophthalmitis of the left eye after injury from a water gun. Empirical treatment for endophthalmitis was started on presentation to the ophthalmologist. After the identification of the pathogen and a review of the literature, the antibiotic regimen was changed to include intravitreal ampicillin and amikacin with systemic linezolid.

Endophthalmitis caused by E casseliflavus and other vancomycinresistant enterococci are challenging to treat. Rapid identification of vancomycin-resistant enterococcal endophthalmitis is important to guide appropriate antibiotic therapy. Systemic linezolid achieves excellent intravitreal concentrations, and should be used in combination with intravitreal and topical antibiotics.

Key Words: Endophthalmitis; Enterococcus; Enterococcus casseliflavus; Vancomycin-resistant

C ndophthalmitis is caused by the introduction of a pathogen into $\mathrm{E}_{\text {the intraocular space via trauma, ocular surgery, or direct extension }}$ of a superficial eye infection (exogenous endophthalmitis) or hematogenously (endogenous endophthalmitis). Endophthalmitis caused by vancomycin-resistant enterococci (VRE) is rare, described in only a few published case reports. One type of VRE, Enterococcus casseliflavus is inherently resistant to vancomycin due to the chromosomally encoded vanC gene, and has been reported once as a cause of endogenous endophthalmitis $(1,2)$. We report the first case of exogenous endophthalmitis caused by $E$ casseliflarus via the unique mechanism of high-velocity water stream trauma from a toy water gun.

For VRE infections, ampicillin or amoxicillin are reasonable antibiotic choices if the isolate is susceptible. In the absence of high-level aminoglycoside resistance, ampicillin may be combined with an aminoglycoside for a synergistic effect (3). Other clinically available antibiotics with activity against VRE include: linezolid, daptomycin and tigecycline $(4,5)$.

\section{L'endophtalmie exogène attribuable à}

l'Enterococcus casseliflavus : rapport de cas et exposé sur le traitement de l'infection intra-oculaire par des entérocoques résistant à la vancomycine

HISTORIQUE : L'endophtalmie est rarement attribuable aux entérocoques, et les cas découlant d'entérocoques résistant à la vancomycine le sont encore plus. Étant donné la piètre biodisponibilité de nombreux antibiotiques dans la cavité vitréenne, il faut tenir compte de facteurs particuliers lors de la sélection du traitement de ces infections. Les auteurs présentent le premier cas d'endophtalmie exogène causée par une Enterococcus casseliflavus contractée après un traumatisme imputable au mécanisme unique de jet d'eau à grande vitesse propulsé par un pistolet à eau.

Un garçon de quatre ans auparavant en santé a consulté à cause d'une endophtalmie de l'œil gauche après une blessure contractée par un pistolet à eau. L'ophtalmologiste a prescrit un traitement empirique dès la consultation. Après avoir confirmé l'agent pathogène et analysé les publications, il a modifié la posologie antibiotique pour inclure de l'ampicilline intravitréenne et de l'amikacine combinée à de la linézolide systémique.

L'endophtalmie causée par l'E casseliflavus et d'autres entérocoques résistant à la vancomycine est difficile à traiter. Il est important de déceler rapidement l'endophtalmie par entérocoque résistant à la vancomycine pour orienter l'antibiothérapie. La linézolide systémique, qui assure d'excellentes concentrations intravitréennes, devrait être combinée à des antibiotiques intravitréens et topiques.

Treatment of bacterial endophthalmitis is difficult due to the severe and rapid retinal damage that occurs as a result of bacterial growth and inflammatory response, and it involves a combination of intravitreal and systemic antibiotics with vitrectomy (6). Although there is a lack of strong evidence supporting an added benefit of systemic antibiotics, they are recommended in severe cases of endophthalmitis and routinely for exogenous endophthalmitis $(6,7)$. Poor penetration of systemic or topical antibiotics into the vitreous chamber makes administration of antibiotics to prevent further bacterial growth challenging, especially in the context of resistant organisms such as VRE.

\section{CASE PRESENTATION}

A previously healthy, fully immunized, four-year-old boy, with no previous visual issues, presented with endophthalmitis of the left eye. He and his siblings had been playing with water guns several hours before presentation, and water was squirted into his eye. The water was from

${ }^{1}$ Department of Medical Microbiology and Immunology, University of Alberta; ${ }^{2}$ Alberta Provincial Laboratory for Public Health; ${ }^{3}$ DynaLIFE ${ }_{\text {Dx }}$

Diagnostic Laboratory Services; ${ }^{4}$ Department of Laboratory Medicine and Pathology; ${ }^{5}$ Department of Ophthamology; ${ }^{6}$ Department of

Pediatrics, University of Alberta, Edmonton, Alberta

Correspondence: Dr Sarah Forgie, Department of Pediatrics, Edmonton Clinic Health Academy, 3-558D 1140587 Avenue, Edmonton,

Alberta T6G 2J3. Telephone 780-248-5540, e-mail s.forgie@ualberta.ca 
a wading pool that had been filled with tap water the same day. The child experienced acute onset of pain and, approximately $2 \mathrm{~h}$ later, reported 'white dots' obscuring his vision. Six hours after the initial insult, his mother noticed that his left cornea was cloudy and his conjunctiva was red. He was immediately taken to his local hospital and assessed promptly by the local ophthalmologist. His pupils were asymmetric, his conjunctiva was injected on the left and there was corneal opacity. The remainder of his physical examination was unremarkable. Given the mechanism of the injury, the diagnosis was not clear, and the ophthalmologist transferred him to a tertiary eye care centre $5 \mathrm{~h}$ away for further management. The child presented to the tertiary care centre with severe anterior chamber inflammation, miosis and inferior hypopyon. The vitreous cavity was filled with purulent debris with no view of the fundus. B-scan ultrasonography revealed vitritis with no foreign body. Given the unusual mechanism of injury, it was not clear whether this was endophthalmitis or a severe inflammatory response to trauma. The Retina Service was consulted and, after assessment, the child was scheduled for surgery

Approximately $26 \mathrm{~h}$ after the injury, the child underwent anterior chamber exploration and pars plana vitrectomy. Vitrectomy allowed visualization of white retinal infiltrates and the absence of a foreign body. After vitrectomy wash out, the vitreous chamber was injected with $1 \mathrm{mg}$ vancomycin, $2.25 \mathrm{mg}$ ceftazidime and $1 \mathrm{mg}$ dexamethasone (routine drugs administered for exogenous endophthalmitis) (8). Topical and systemic medications were also administered including: one drop $0.5 \%$ moxifloxacin hourly, one drop $1 \%$ prednisolone daily, one drop $2 \%$ homatropine every $12 \mathrm{~h}, 30 \mathrm{mg} / \mathrm{kg} /$ day oral ciprofloxacin divided every $12 \mathrm{~h}$ and $60 \mathrm{mg} / \mathrm{kg} /$ day intravenous vancomycin divided every $6 \mathrm{~h}$.

Gram stain of the vitreous fluid revealed $>25$ polymorphonuclear leukocytes and >25 Gram-positive cocci in pairs and chains (intracellular and extracellular) per $1000 \times$ field. After $18 \mathrm{~h}$ of incubation on blood agar, there was growth of yellow-pigmented, alpha-hemolytic colonies, which were Gram-positive cocci in pairs and chains. Mass spectrometry (Vitek MS BioMérieux, France) identified the organism as E casseliflavus (99.9\% certainty) within $45 \mathrm{~min}$. The medical microbiologist was immediately alerted of the identification of this intrinsically vancomycin-resistant organism and treatment options were discussed with the pediatric infectious disease and ophthalmology physicians.

The discussion prompted an immediate return to the operating room for additional intravitreal antibiotics and a repeat vitreous washout. Using the local antibiogram for this organism, published susceptibilities and the experience of Hillier et al $(9,10)$ treating an E gallinarum endophthalmitis secondary to a metallic foreign body, the treatment plan consisted of intravitreal ampicillin $(50 \mathrm{mg})$ and amikacin $(400 \mathrm{mg})$, as well as intravenous ampicillin $(300 \mathrm{mg} / \mathrm{kg} / \mathrm{day}$ divided every $6 \mathrm{~h}$ ). Topical treatment consisted of $0.3 \%$ gentamicin (one drop four times per day) and $1 \%$ prednisolone (one drop four times per day). Twelve hours after the antibiotic change to ampicillin, linezolid ( $30 \mathrm{mg} / \mathrm{kg} /$ day divided every $8 \mathrm{~h}$ ) was added. Systemic and topical antimicrobials were continued for 14 days. Table 1 summarized the antibiotic susceptibilities.

The patient was closely monitored in the ophthalmology clinic. The hypopyon did not recur and the vitreous cavity remained opaque with no view of the fundus at 10 days after the initial anterior chamber washout with vitrectomy. The visual acuity began to decrease three weeks postincident; however, clinical examination did not support repeat infection and it was likely due to development of outer cortical vitreous separation causing vitreous debris. Over time, the vitreous cavity and anterior segment cleared, and vision improved to 20/400 at seven weeks, 20/400 at 17 weeks and 20/70 at 16 months postincident.

\section{DISCUSSION}

The present case highlights the importance of interdisciplinary medical care, and the effective use of laboratory technology to assure early and appropriate antimicrobial treatment. Rapid identification of this isolate was achieved using mass spectrometry, a process that previously would take $8 \mathrm{~h}$ to $12 \mathrm{~h}$. In addition, effective communication between the

\section{TABLE 1} Susceptibilities of the Enterococcus casseliflavus isolate
compared with EUCAST and CLSI breakpoints

\begin{tabular}{lcccc}
\hline Antibiotic & Isolate MIC & Interpretation & EUCAST $^{\dagger}$ & CLSI $^{\ddagger}$ \\
\hline Ampicillin & $\leq 2$ & Sensitive & $\leq 4$ & $\leq 8$ \\
Vancomycin & 4 & Resistant $^{*}$ & $\leq 4$ & $\leq 4$ \\
Gentamicin synergy & N/A & Sensitive & $\leq 128$ & $\leq 500$ \\
Linezolid & 2 & Sensitive & $\leq 4$ & $\leq 2$ \\
\hline
\end{tabular}

Data presented as $\mu \mathrm{g} / \mathrm{mL}$. Minimum inhibitory concentrations (MICs) were determined using the Vitek 2, GP 67 card (BioMérieux, France). Vitek 2 reports gentamicin synergy as sensitive or resistant without an MIC. *Vancomycin was reported resistant due to the intrinsic carriage of VanC in $\mathrm{E}$ casseliflavus. ${ }^{\dagger}$ Data adapted from reference 7. ${ }^{\ddagger}$ Data adapted from reference 6. CLSI Clinical Laboratory Standards Institute; EUCAST European Committee on Antimicrobial Susceptibility Testing; N/A Not available

medical microbiologist and the clinical team allowed prompt treatment changes. This stresses the importance of interdisciplinary teams in the health care environment, especially when dealing with challenging infections such as VRE endophthalmitis.

Early vitrectomy is an important component for treating severe endogenous or postsurgical endophthalmitis, and is routinely performed for exogenous endophthalmitis because it improves outcomes and enhances clearance of bacteria, inflammatory cells and debris (6,8). During vitrectomy, iatrogenic complications such as retinal detachment may occur; therefore, repeat vitrectomy is avoided unless intravitreal debris persist $(8,11)$. In our case, vitrectomy was performed in an acceptable time frame given that the child came from a rural area and the initial diagnosis was initially ambiguous. Repeat vitreous washout and the administration of additional intravitreal antibiotics was performed because VRE was isolated and it was resistant to the initial intravitreal antibiotic regimen.

In exogenous endophthalmitis, vision is restored to 20/40 or better in $15 \%$ to $40 \%$ of cases and, in acute postoperative endophthalmitis, approximately $50 \%$ have visual acuity of $20 / 40$ or better and $15 \%$ to $36 \%$ have visual acuity of 20/200 (6). Therefore, the outcome in the present case (visual acuity of 20/70) is acceptable given that the treatment of VRE is challenging, especially when the infection is in the vitreous chamber where there is poor penetration of systemic or topical antibiotics.

There are no published data regarding the penetration of ampicillin into the human vitreous chamber. Animal data reveal that when administered intravenously, levels of ampicillin in the vitreous fluid were approximately 2-log less than in the serum (12), and when administered orally, amoxicillin levels in the vitreous fluid were approximately 1.5 - to $2-\log$ less effective at killing Micrococcus luteus than levels in serum (13). Therefore, extrapolating from animal data, there is poor penetration of ampicillin and amoxicillin into the vitreous fluid.

Gentamicin also has poor penetration into the vitreous fluid. Human studies reveal no detectable gentamicin in the vitreous fluid when doses were administered intramuscularly $(1.6 \mathrm{mg} / \mathrm{kg})$ or subconjunctivally $(40 \mathrm{mg})(14)$. These data are supported with animal studies (15). Furthermore, intravitreal gentamicin has been linked to macular infarction; however, intravitreal amikacin has a lower incidence of macular infarction (16).

Linezolid resistance in Enterococcus is rare and there is evidence that it penetrates the vitreous chamber. Administration of two doses of oral linezolid (600 mg every $12 \mathrm{~h}$ ) in noninflamed eyes, achieved a mean $( \pm \mathrm{SD})$ concentration in the vitreous fluid of $5.7 \pm 2.7 \mu \mathrm{g} / \mathrm{mL}$ (versus $10.3 \pm 4.1 \mu \mathrm{g} / \mathrm{mL}$ in the serum) $6 \mathrm{~h}$ postdose (see Table 1 for susceptibility breakpoints). Using the same linezolid regimen, Horcadjada et al (17) found concentrations in the vitreous fluid to be higher than $4 \mu \mathrm{g} / \mathrm{mL}$ in the majority of patients studied, $12 \mathrm{~h}$ after the second dose. When only one dose was administered, it was difficult to achieve levels higher than $2 \mu \mathrm{g} / \mathrm{mL}$ (17-19). Unlike systemic linezolid, 
topical administration of linezolid in animal studies revealed negligible penetration into the vitreous fluid (20). Therefore, when administered orally or intravenously, linezolid concentrations in the vitreous chamber are above the minimum inhibitory concentration for most Enterococci.

Daptomycin is another alternative for treatment of VRE; however, there are limited data regarding its penetration into the vitreous chamber. One case of endogenous endophthalmitis caused by methicillinresistant Staphylococcus aureus bacteremia, refractory to vancomycin and linezolid treatment in a patient experiencing chronic renal failure demonstrated vitreous fluid levels three times the Clinical and Laboratory Standards Institute susceptible breakpoint of $\leq 4 \mu \mathrm{g} / \mathrm{mL} 42 \mathrm{~h}$ after one dose of intravenous daptomycin (21).

Tigecycline is a potential antibiotic to use for VRE infections; however, topical or systemic use of tigecycline for eye infections has not been investigated. Tigecycline also has an unfavourable side effect profile and a United States Food and Drug Administration black box warning against its intravenous use (22).

In the present case, no source of the endophthalmitis other than the water stream trauma from the toy water gun was identified. Water toys and squirt guns are capable of generating pressurized water streams that pose a risk for increased intraocular pressure and ocular injury (23). While Enterococci are not typically associated with water, we speculate that the wading pool (that was used to fill the water guns) may have been contaminated with fecal matter. Given the timing of the insult, the clinical presentation and the lack of another identifiable source, the present case is likely one of E casseliflarus exogenous endophthalmitis caused by high-velocity water stream trauma from a toy water gun.

\section{REFERENCES}

1. Cetinkaya Y, Falk P, Mayhall CG. Vancomycin-resistant Enterococci. Clin Microbiol Rev 2000;13:686-707.

2. Sambhav K, Mathai A, Reddy AK, Reddy BV, Bhatia K, Balne PK. Endogenous endophthalmitis caused by Enterococcus casseliflavus. J Med Microbiol 2011;60:670-2.

3. Habib G, Hoen B, Tornos P, et al. Guidelines on the prevention, diagnosis, and treatment of infective endocarditis (new version 2009): The Task Force on the Prevention, Diagnosis, and Treatment of Infective Endocarditis of the European Society of Cardiology (ESC). Endorsed by the European Society of Clinical Microbiology and Infectious Diseases (ESCMID) and the International Society of Chemotherapy (ISC) for Infection and Cancer. Eur Heart J 2009;2369-413.

4. Clinical Laboratory Standards Institute: Performance Standards for Antimicrobial Susceptibility Testing; Twenty-Third Informational Supplement. Clinical and Laboratory Standards Institute 2013, CLSI Document M100-S23.

5. European Committee on Antimicrobial Testing: Breakpoint tables for interpretation of MICs and zone diameters. 2013, version 3.1.

6. Vaziri K, Schwartz SG, Kishor K, Flynn HW. Endophthalmitis: State of the art. Clin Ophthalmol 2015;9:95-108.

7. Flynn HW, Scott IU. Legacy of the endophthalmitis vitrectomy study. Arch Ophthalmol 2008;126:559-61.

8. Callegan MC, Engelbert M, Parke DW, Jett BD, Gilmore MS. Bacterial endophthalmitis: Epidemiology, therapeutics, and bacterium-host interactions. Clin Microbiol Rev 2002;15:111-24.

9. Choi S-H, Lee S-O, Kim TH, et al. Clinical features and outcomes of bacteremia caused by Enterococcus casseliflavus and Enterococcus gallinarum: Analysis of 56 cases. Clin Infect Dis 2004;38:53-61.

10. Hillier RJ, Arjmand P, Rebick G, Ostrowski M, Muni RH. Post-traumatic vancomycin-resistant enterococcal endophthalmitis. J Ophthalmic Inflamm Infect 2013;3:42.

11. Kuhn F, Gini G. Ten years after... are findings of the Endophthalmitis Vitrectomy Study still relevant today? Albrecht von Graefes Arch Klin Ophthalmol 2005;243:1197-9.

12. Röber H, Göring W, Sous H, Reim M. Concentration of ampicillin in the vitreous after cryocoagulation. Albrecht v Graefes Arch klin exp Ophthal 1977;204:275-80.

13. Faigenbaum SJ, Boyle GL, Prywes AS, Abel RJ, Leopold IH. Intraocular penetrating of amoxicillin. Am J Ophthalmol 1976;82:598-603.

\section{CONCLUSION}

Endophthalmitis caused by E casseliflavus and other VRE are challenging to treat, due to reduced antimicrobial options and the poor penetration of topical and systemic antibiotics into the vitreal space. Therefore, rapid identification of the organism and knowledge of antimicrobial penetration into the vitreal space is important to guide therapy. Systemic linezolid alone may achieve intravitreal concentrations above the minimum inhibitory concentration for VRE; however, based on the literature, a combination of antibiotics delivered via intravitreal injection, systemic and topical routes should be used to treat VRE endophthalmitis.

DISCLOSURES: The authors have no financial relationships or conflicts of interest to declare.

AUTHOR CONTRIBUTIONS: All authors read and approved the final manuscript. $\mathrm{BMB}$ was involved in the clinical management of the patient, performed literature review and drafted the manuscript. SF was the pediatric infectious disease consultant in the present case. $\mathrm{BH}$ was the opthalmologist involved in the case and obtained consent from the patient's parents. SK was the medical microbiologist in the present case. All authors were involved in critical appraisal and revision of the manuscript.

ACKNOWLEDGEMENTS: The authors are grateful to the staff in the Department of Microbiology at DynaLIFEDx for the laboratory work performed for the present case.

14. Rubinstein E, Goldfarb J, Keren G, Blumenthal M, Treister G. The penetration of gentamicin into the vitreous humor in man. Invest Ophthalmol Vis Sci 1983;24:637-9.

15. Verbraeken H, Verstraete A, Van de Velde E, Verschraegen G. Penetration of gentamicin and ofloxacin in human vitreous after systemic administration. Graefes Arch Clin Exp Ophthalmol 1996;234(Suppl 1):S59-65.

16. D’Amico DJ, Caspers-Velu L, Libert J, et al. Comparative toxicity of intravitreal aminoglycoside antibiotics. Am J Ophthalmol 1985;100:264-75.

17. Horcajada JP, Atienza R, Sarasa M, Soy D, Adan A, Mensa J. Pharmacokinetics of linezolid in human non-inflamed vitreous after systemic administration. J Antimicrob Chemother 2009;63:550-2.

18. Fiscella RG, Lai WW, Buerk B, et al. Aqueous and vitreous penetration of linezolid (Zyvox) after oral administration. Ophthalmol 2004:111:1191-5.

19. Ciulla TA, Comer GM, Peloquin C, Wheeler J. Human vitreous distribution of linezolid after a single oral dose. Retina 2005;25:619-24.

20. Saleh M, Jehl F, Dory A, et al. Ocular penetration of topically applied linezolid in a rabbit model. J Cataract Refract Surg 2010;36:488-92.

21. Sheridan KR, Potoski BA, Shields RK. Presence of adequate intravitreal concentrations of daptomycin after systemic intravenous administration in a patient with endogenous endophthalmitis. J Human Pharmacol Drug Ther 2010;30:1247-51.

22. Center for Drug Evaluation, Research: Drug Safety and Availability - FDA Drug Safety Communication: FDA warns of increased risk of death with IV antibacterial Tygacil (tigecycline) and approves new Boxed Warning. US Food and Drug Administration 2013. <www.fda.gov/Drugs/DrugSafety/ucm369580.htm> (Accessed September 3, 2015).

23. Duma SM, Bisplinghoff JA, Senge DM, McNally C, Alphonse VD. Eye injury risk from water stream impact: Biomechanically based design parameters for water toy and park design. Curr Eye Res 2012;37:279-85. 


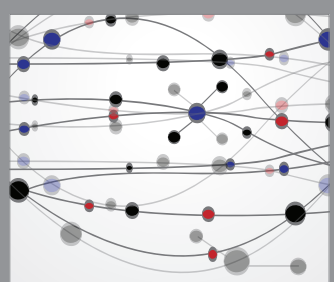

The Scientific World Journal
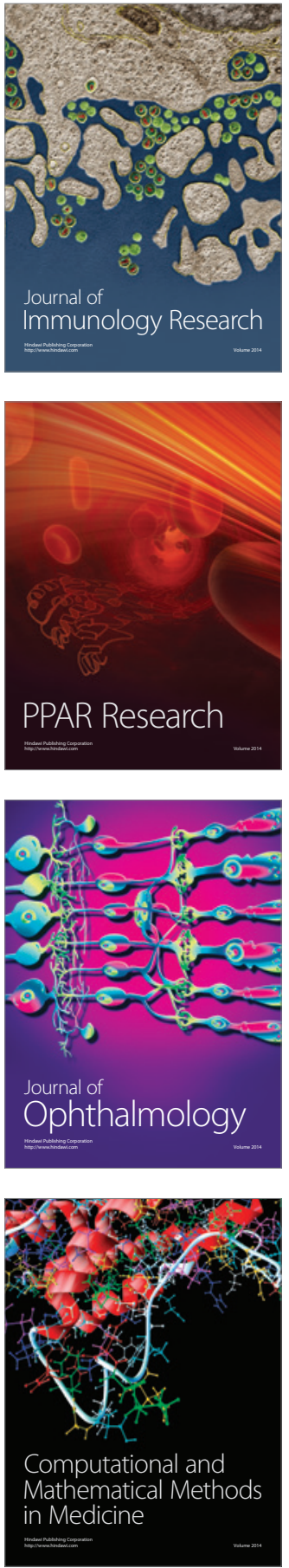

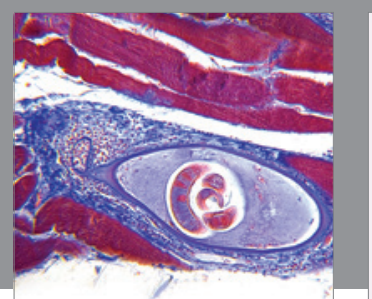

Gastroenterology Research and Practice

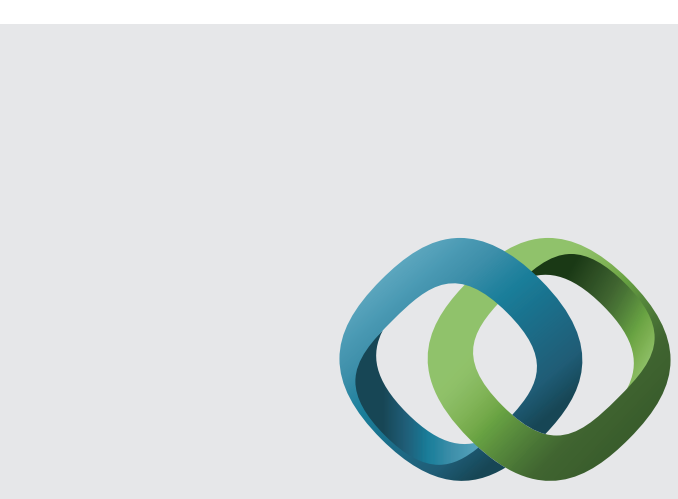

\section{Hindawi}

Submit your manuscripts at

http://www.hindawi.com
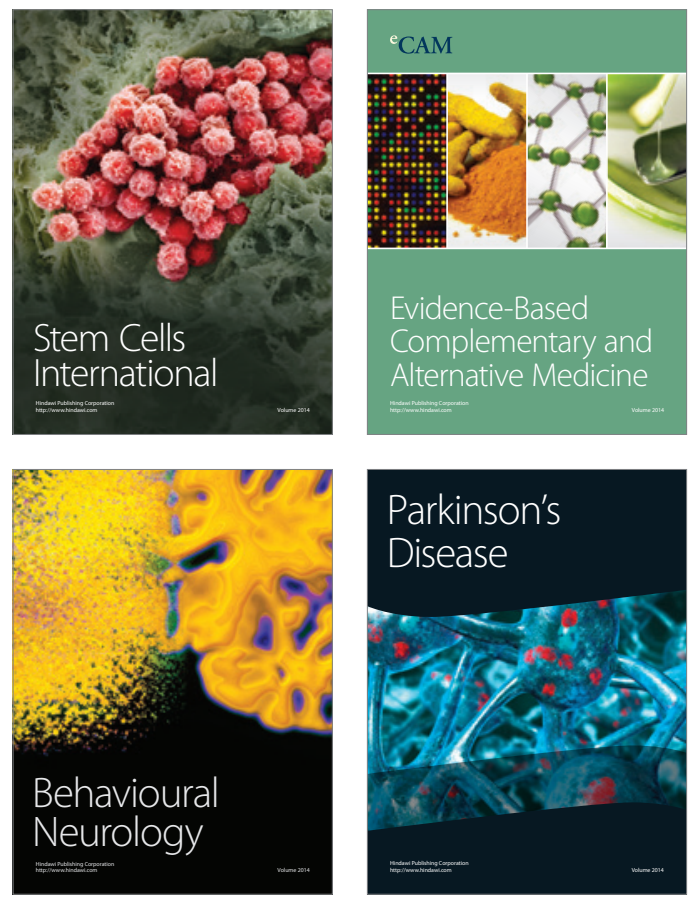
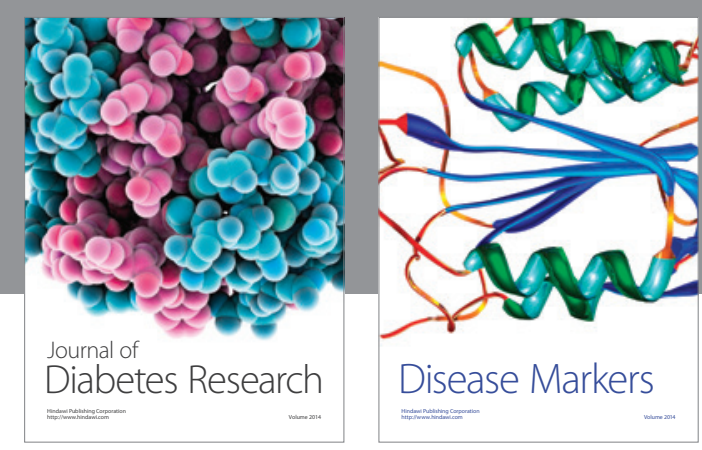

Disease Markers
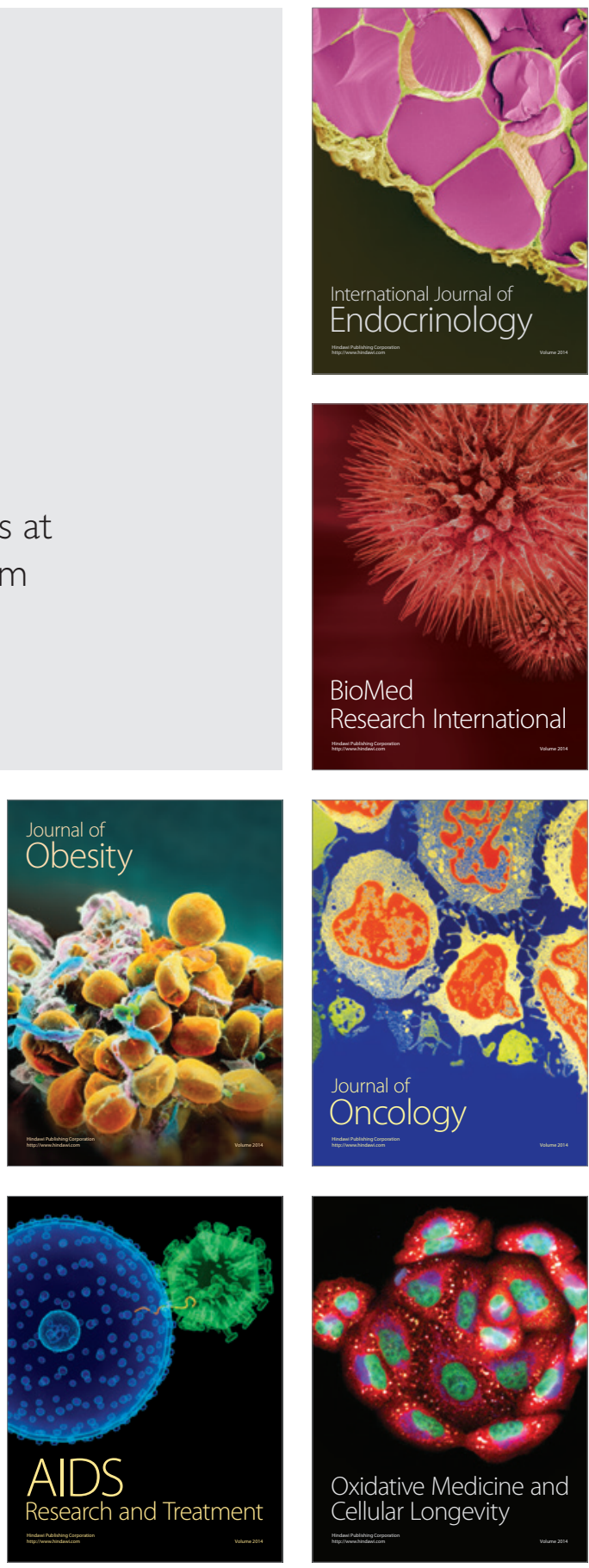